\title{
The electromyographic threshold in boys and men
}

Brynlynn Pitt ${ }^{1}$, Raffy Dotan ${ }^{1}$, Jordan Millar ${ }^{1}$, Devon Long ${ }^{1}$, Craig Tokuno ${ }^{2}$, Thomas O’Brien ${ }^{3}$, Bareket Falk ${ }^{2}$

1. Applied Physiology Laboratory, Faculty of Applied Health Sciences, Brock University, St. Catharines, Ontario, Canada

2. Department of Kinesiology, Faculty of Applied Health Sciences, Brock University, St. Catharines, Ontario, Canada

3. Research Institute for Sport and Exercise Sciences, Faculty of Science, Liverpool John Moores University, Liverpool, UK

\section{Corresponding author:}

Raffy Dotan, Faculty of Applied Health Sciences

Brock University 500 Glenridge Ave

St. Catharines, ON, Canada

L2T 2 Y1

Tel: $9056885550 \times 5257$

Email: rdotan@brocku.ca

Running title: Electromyographic threshold in boys and men

Subject area: Exercise physiology

Word count: 4478 


\begin{abstract}
Background: Children have been shown to have higher lactate- $\left(\mathrm{La}_{\mathrm{Th}}\right)$ and ventilatorythresholds $\left(\mathrm{Ve}_{\mathrm{Th}}\right)$ than adults, which might be explained by lower levels of type-II motor-unit (MU) recruitment. However, the electromyographic threshold $\left(\mathrm{EMG}_{\mathrm{Th}}\right)$, regarded as indicating the onset of accelerated type-II MU recruitment, has been investigated only in adults. Purpose: To compare the relative exercise intensity at which the $\mathrm{EMG}_{\mathrm{Th}}$ occurs in boys $v$ s. men. Methods:

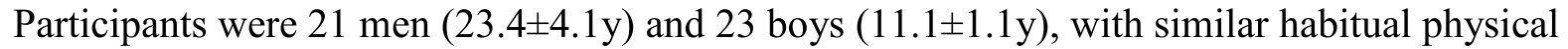
activity and peak oxygen consumption $\left(\mathrm{VO}_{2} \mathrm{pk}\right)\left(49.7 \pm 5.5 \mathrm{vs} .50 .1 \pm 7.4 \mathrm{ml} \cdot \mathrm{kg}^{-1} \cdot \mathrm{min}^{-1}\right.$, respectively). Ramped cycle-ergometry was conducted to volitional exhaustion with surface EMG recorded from the right and left vastus lateralis muscles throughout the test $(\sim 10 \mathrm{~min})$. The composite right-left EMG root mean-square $\left(\mathrm{EMG}_{\mathrm{RMS}}\right)$ was then calculated per pedal revolution. The $\mathrm{EMG}_{\mathrm{Th}}$ was then determined as the exercise intensity at the point of least residual sum of squares for any two-regression-line division of the $\mathrm{EMG}_{\mathrm{RMS}}$ plot. Results: $\mathrm{EMG}_{\mathrm{Th}}$ was detected in $20 / 21$ of the men $(95.2 \%)$ and only in $18 / 23$ of the boys $(78.3 \%)$. The boys' EMG $_{\text {Th }}$ was significantly higher than the men's $(86.4 \pm 9.6$ vs. $79.7 \pm 10.0 \%$ of peak power-output at exhaustion; $p<0.05)$. The pattern was similar when $\mathrm{EMG}_{\mathrm{Th}}$ was expressed as percentage of $\mathrm{VO}_{2}$ pk. Conclusions: The boys' higher $\mathrm{EMG}_{\mathrm{Th}}$ suggests delayed and hence lesser utilisation of type-II MU in progressive exercise, compared with men. The boys- men $\mathrm{EMG}_{\mathrm{Th}}$ differences were of similar magnitude to those shown for $\mathrm{La}_{\mathrm{Th}}$ and $\mathrm{Ve}_{\mathrm{Th}}$, further suggesting a common underlying factor.
\end{abstract}

Key words: Children, Exercise, Motor unit activation 


\section{Abbreviations}

EMG - Electromyography

$\mathrm{EMG}_{\mathrm{Th}}-$ ElectroMyoGraphic Threshold

HR - Heart Rate

$\mathrm{La}_{\mathrm{Th}}-$ Lactate Threshold

MU / MUs - Motor Unit / Motor Units

MVC - Maximal Voluntary Contraction

OBLA - Onset of Blood Lactate Accumulation

PHV - Peak Height Velocity

Pmax - Maximal power attained at end of the $\mathrm{EMG}_{\mathrm{Th}}$ test

$\mathrm{PVO}_{2} \mathrm{pk}$ - Peak aerobic power (mechanical power output corresponding to $\mathrm{VO}_{2} \mathrm{pk}$ )

RER - Respiratory Exchange Ratio

RMS - Root Mean Square

SD - Standard Deviation

$\mathrm{Ve}_{\mathrm{Th}}-$ Ventilatory / Gas-Exchange Threshold

$\mathrm{VO}_{2}-$ Oxygen Consumption

$\mathrm{VO}_{2} \mathrm{pk}$ - Peak oxygen consumption 


\section{Introduction}

Children's response to exercise is physiologically and functionally different from adults'. For example, compared with adults, children demonstrate lower body-size-normalized maximal isometric strength (Falk et al. 2009) and short-term power (Beneke et al. 2007; Van Praagh and Dore 2002), higher ventilatory threshold $\left(\mathrm{Ve}_{\mathrm{Th}}\right)$ (Klentrou et al. 2006) and lactate threshold $\left(\mathrm{La}_{\mathrm{Th}}\right)$ (Simon et al. 1981; Tanaka and Shindo 1985). In terms of neuromuscular function, children have been shown to have lower motor-unit (MU) activation of the knee extensor muscles (Blimkie 1989; O'Brien et al. 2009, 2010), and a lower mean power frequency during sustained maximal voluntary contraction (MVC) (Halin et al. 2003). According to the sizeprinciple (Henneman et al. 1965), the lower level of voluntary recruitment implies that children activate their higher threshold, fast-twitch, type-II MUs to a lesser extent than do adults. The lesser activation of type-II MUs and greater reliance on slow-twitch, type-I MUs may, in turn, explain many performance, metabolic, and neuro-motor differences between children and adults, beyond isometric muscle strength (Dotan et al. 2012). Direct supportive evidence for this differential MU activation hypothesis is lacking due to technical or ethical constraints associated with invasive techniques. Hence, new investigative approaches ought to be explored in attempting to further support or refute the hypothesis.

Currently, no technique is available for directly monitoring the proportion of active type-I vs. type-II MUs. Furthermore, invasive procedures that might be available for adults (e.g., needle electrodes) are not ethically acceptable for children. A non-invasive technique that is widely accepted as being able to discern the onset of type-II MU activation, in adults, is the electromyographic threshold $\left(\mathrm{EMG}_{\mathrm{Th}}\right)$ (Candotti et al. 2008; Edwards and Lippold 1956; Hug et al. 2006b; Hug et al. 2003; Lucia et al. 1999; Maestu et al. 2006; Moritani and deVries 1978; 
Moritani et al. 1993; Moritani et al. 1984; Nagata et al. 1981; Petrofsky 1979; Tikkanen et al. 2012). The $\mathrm{EMG}_{\mathrm{Th}}$ is defined as a non-linear increase, or upward inflection, in the EMG signal during progressive exercise of increasing intensity (Miyashita and Kanehisa 1980; Moritani and deVries 1978). The $\mathrm{EMG}_{\mathrm{Th}}$ concept is supported by evidence of orderly depletion of glycogen first in type- $\mathrm{I}$ and $\mathrm{II}_{\mathrm{A}}$, followed by $\mathrm{II}_{\mathrm{AX}}\left(\mathrm{II}_{\mathrm{AB}}\right)$, and finally $\mathrm{II}_{\mathrm{X}}\left(\mathrm{II}_{\mathrm{B}}\right)$ muscle fibres at increasing workloads (Vollestad and Blom 1985), and by increasing muscle fibre conduction velocity at progressively higher power outputs, suggesting progressive recruitment of large, highconduction-velocity MUs with increasing muscle force (Farina et al. 2004).

In adults, the $\mathrm{EMG}_{\mathrm{Th}}$ has been investigated in untrained as well as trained individuals, mostly in cycling and running, but also in upper-extremity exercise modes (Bearden and Moffatt 2001; Candotti et al. 2008; Chwalbinska-Moneta et al. 1994; Chwalbinska-Moneta et al. 1998; Hug et al. 2004; Hug et al. 2006b; Hug et al. 2003; Lucia et al. 1999; Moritani et al. 1993; Nagata et al. 1981; Takaishi et al. 1992; Taylor and Bronks 1994; Tikkanen et al. 2012; Viitasalo et al. 1985), and in a wide range of muscles (Bearden and Moffatt 2001; Chwalbinska-Moneta et al. 1994; Chwalbinska-Moneta et al. 1998; Hug et al. 2006b; Hug et al. 2003; Lucia et al. 1999; Moritani et al. 1984; Nagata et al. 1981; Takaishi et al. 1992). Alongside the $\mathrm{EMG}_{\mathrm{Th}}$, a number of studies also determined the $\mathrm{Ve}_{\mathrm{Th}}$ (Nagata et al. 1981; Tikkanen et al. 2012), the La $\mathrm{Th}_{\mathrm{Th}}$ (Candotti et al. 2008; Chwalbinska-Moneta et al. 1998; Moritani et al. 1993; Moritani et al. 1984; Nagata et al. 1981), and the onset of blood lactate accumulation (OBLA) (Tikkanen et al. 2012). These thresholds highly correlated with the $\mathrm{EMG}_{\mathrm{Th}}$, although they did not necessarily coincide. This inter-threshold correlation could be expected as increased activation of the more glycolytic typeII MUs, presumed to occur at the $\mathrm{EMG}_{\mathrm{Th}}$, implies higher lactate production and accumulation, increased acidosis, and elevated ventilatory drive. 
The $\mathrm{EMG}_{\mathrm{Th}}$ has not been studied in children. Thus, the purpose of this study was to compare the relative exercise intensity at which $\mathrm{EMG}_{\mathrm{Th}}$ occurs in children $v s$. adults. Given the close relationships between $\mathrm{EMG}_{\mathrm{Th}}$ and the $\mathrm{La}_{\mathrm{Th}}$ and $\mathrm{Ve}_{\mathrm{Th}}$ seen in adults, and the observed higher exercise intensity at which the latter thresholds occur in children, it was hypothesized that the $\mathrm{EMG}_{\mathrm{Th}}$ would also occur at higher relative exercise intensities in children than in adults. Such findings would suggest a different muscle activation regimen, in which children recruit type-II MUs later and to a lesser extent than do adults.

\section{Methods}

\section{Participants}

All tests and procedures complied with the Helsinki declaration and were cleared by Brock University's Research Ethics Board. Twenty three boys, aged 8-13 y, and 21 men, aged 18-32 y, with similar weekly physical activity history and peak oxygen consumption $\left(\mathrm{VO}_{2} \mathrm{pk}\right)$, volunteered for the study. A summary of participants' characteristics is provided in Table 1. Written informed consent was provided by all adult participants and by the boys' parents or guardians prior to enrolment in the study. All boys provided their informed assent to participate. Participants completed questionnaires regarding medical history, physical activity (Godin and Shephard 1985) and sport training history. All participants were physically active and all child participants were involved in some form of organized, competitive sports. Boys were significantly smaller than men but no differences were observed in body composition or maximal oxygen consumption. Sexual maturity in the boys, as determined by self-assessment of secondary sex characteristics [pubic hair (Tanner 1962)], ranged from stages 1 to 4, with eight boys at stage 1 , eight at stage 2 , five at stage 3 , and one at stage 4 . One participant's sexual 
maturity value was excluded from analysis due to misreport concerns. Years to age of Peak Height Velocity (PHV) for the boys, as estimated using the Mirwald equation (Mirwald et al. 2002), averaged $-2.30 \pm 0.63$ years ( $n=18$; range: -0.88 to -3.59$)$.

[Table 1]

\section{Experimental Protocol}

Participants made two laboratory visits. During the first visit, participants were informed of all tests and procedures to take place over both visits. Anthropometric variables such as height, body mass, and percent body fat (\%Fat) were measured. Skinfold thickness was measured in triplicate using Harpenden calipers (British Indicators, Herts, England) and the median value at each site was used. Skinfold thickness (triceps and subscapula) was used to estimate percent body fat using age- and maturity-specific equations (Slaughter 1988). Pubertal stage and physical activity and training history were also determined. Participants were then familiarised with the crank-length-adjustable cycle-ergometer (Excalibur Sport, Lode, Groningen, The Netherlands). Seat and handlebar positioning were determined and recorded for re-use in the subsequent visit. Proper crank length was individually determined at 5-mm increments as a function of inseam length. Participants then proceeded to perform a submaximal and maximal progressive cycling test to determine aerobic capacity (see below).

The second visit was scheduled 3-7 days following the first visit and included a maximal progressive cycling test for the determination of the $\mathrm{EMG}_{\mathrm{Th}}$ (see below).

\section{Exercise Testing}

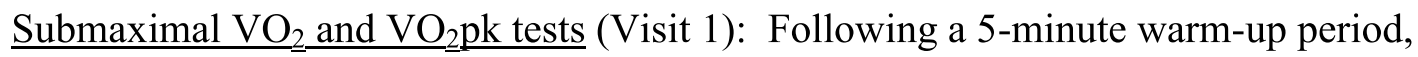
participants commenced an incremental exercise protocol consisting of 3-5 submaximal stages to determine the $\mathrm{VO}_{2}$-vs.-power relationship. Stages were 3.5- and 4-min long for the boys and 
the men, respectively. Boys started out at $40-60 \mathrm{~W}$ and progressed in $15-20 \mathrm{~W}$ increments at each subsequent stage. Men started at $80-100 \mathrm{~W}$ with $30-40 \mathrm{~W}$ increments. These submaximal stages were used to determine the steady-state $\mathrm{VO}_{2}$ in several progressive power output levels.

Following the completion of the submaximal stages, participants recovered for 10-20-min. Participants then performed an incremental exercise protocol to volitional exhaustion for the determination of peak aerobic power $\left(\mathrm{PVO}_{2} \mathrm{pk}\right.$; the power output, in Watts, corresponding to $\left.\mathrm{VO}_{2} \mathrm{pk}\right)$.Workload was increased every minute $\left(10\right.$ and $20 \mathrm{~W} \cdot \mathrm{min}^{-1}$, for the boys and men, respectively) until volitional exhaustion. Pedalling rate was maintained at a minimum of 80 revolutions per minute $(\mathrm{rpm})$.

Heart rate was determined using a heart rate monitor (Timex Personal Heart Rate Monitor, Timex Group Inc., Toronto, ON) throughout the test. Expired gas was collected and analyzed using the Moxus metabolic cart (AEI technologies, PA, USA), calibrated prior to each test. $\mathrm{VO}_{2}$ pk was determined as the average of the highest $\mathrm{VO}_{2}$ values attained over three consecutive 15 -s periods.

$\underline{\text { EMG }}_{\text {Th }}$ test (Visit 2): Ryan \& Gregor (Ryan and Gregor 1992) showed that the monoarticular muscles gluteus maximus, vastus lateralis (VL), vastus medialis, tibialis anterior, and soleus play a relatively invariant role as primary power producers in cycling. Hug et al. (Hug et al. 2006b) showed VL to be the most consistent of eight cycling-involved muscles in demonstrating the $\mathrm{EMG}_{\mathrm{Th}}$. We therefore chose $\mathrm{VL}$ as our tested muscle.

Following a 5-minute warm-up period, participants performed a ramped incremental cycling test to exhaustion. Starting power output was set at $\sim 35-40 \%$ of $\mathrm{PVO}_{2} \mathrm{pk}$ and, based on the previously-determined $\mathrm{PVO}_{2} \mathrm{pk}$, the ramp protocol was set so as to reach volitional exhaustion 
after $\sim 10$ min of exercise. Thus, the mean starting power output for the boys was $51 \pm 12 \mathrm{~W}$ and power output increased on average $1 \mathrm{~W}$ every $6 \mathrm{~s}$. The corresponding values for men were $103 \pm 21 \mathrm{~W}$ and $1 \mathrm{~W}$ every $3 \mathrm{~s}$. Surface EMG, using $10 \mathrm{~mm}^{2}$, bipolar, Ag/Ag surface electrodes (Delsys 2.1, Delsys Inc., Boston, MA), was used to continuously monitor the VL EMG of each leg throughout the test. An area of each thigh at two-thirds on the line from the anterior spina iliaca superior to the superior border of the patella was shaved (if necessary), abraded with skin preparation gel (Nuprep, Weaver and Company, Aurora, CO), and cleaned with rubbing alcohol. Electrodes were placed parallel to the direction of muscle fibres on the medial aspect of the VL and affixed with proprietary double-sided tape. A reference electrode was placed over the spinous process of the seventh cervical vertebra. Participants were instructed and supervised to maintain a pedalling rate as close to $80 \mathrm{rpm}$ as possible throughout the test and verbal encouragement was provided throughout the test and particularly as the participant approached exhaustion.

\section{EMG Data Reduction}

EMG signals were band-pass filtered (20-450 Hz) using the Bagnoli-4 (Delsys Inc., Boston, MA) bioamplifier and sampled at a rate of $1000 \mathrm{~Hz}$ using a Computer-Based Oscillograph and Data Acquisition System (EMGworks Acquisition, Delsys Inc., Boston, MA).

EMG data were analyzed using a dedicated computer algorithm created in MATLAB (2013 version; MathWorks Inc., Natick, MA). For each pedal stroke, a succinct EMG burst was defined and recorded for each leg and the record was pruned at the beginning and end of each stroke to remove any partial or incomplete bursts, if any. The pruned waveform was then de-trended to offset any baseline deviation (i.e., set baseline value to zero). The root mean square (RMS $\mathrm{EMG}_{\mathrm{E}}$ was then calculated for each stroke throughout the entire EMG trace. The onset and offset of 
each $\mathrm{RMS}_{\mathrm{EMG}}$ burst were identified as the points where $\mathrm{RMS}_{\mathrm{EMG}}$ rose or fell, respectively, above or below $10 \%$ of the mean $\mathrm{RMS}_{\mathrm{EMG}}$ value of the entire test record. The mean $\mathrm{RMS}_{\mathrm{EMG}}$ of each burst (i.e., between the onset and offset) was then extracted for $\mathrm{EMG}_{\mathrm{Th}}$ determination.

\section{$\mathbf{E M G}_{\mathrm{Th}}$ Determination}

A composite plot, averaging the $\mathrm{RMS}_{\mathrm{EMG}}$ bursts from both legs, was constructed for each participant. This plot consisted of $\mathrm{RMS}_{\mathrm{EMG}}$ values (one for each pedal stroke) plotted against the test duration. To reduce the internal fluctuation, a trimmed moving average (30-point window in which the lowest 10 and highest 10 values were trimmed off and the mean of the median 10 points was calculated) was applied to the plot (Fig.1). In cases where a drop in the $\mathrm{RMS}_{\mathrm{EMG}}$ at the end of the test was observed in conjunction with a sustained fall below $80 \mathrm{rpm}$ in pedalling cadence, the plot was truncated at the point where cadence began to fall. The $\mathrm{EMG}_{\mathrm{Th}}$ was then determined by a computer algorithm as the point of least residual sum of squares for any two linear regression-line divisions of the data, similar to the approach of Hug et al. (Hug et al. 2006a).

[Figure 1]

Since the algorithm would always determine a point of least residual sum of squares, even when no actual threshold exists, an additional criterion was used to qualify a threshold. Based on previous literature (Hug et al. 2006b), $\mathrm{EMG}_{\mathrm{Th}}$ was expected to occur at relative power outputs higher than $\sim 80 \% \mathrm{P}_{\max }$ in adults, and we hypothesise this to be even higher in children. Based on this assumption, a linear regression line was determined for the initial $70 \%$ of the test duration, corresponding to $\sim 80 \%$ of $\mathrm{P}_{\max }$ (since the $\mathrm{EMG}_{\mathrm{Th}}$ test commenced at a power output equal to $\sim 35-40 \%$ of $\left.\mathrm{PVO}_{2} \mathrm{pk}\right)$. That line was extrapolated to the entire test duration. A 3-standarddeviation (SD) confidence interval was applied above the trend line and extended to the end of 
the trace (Fig.1). An $\mathrm{EMG}_{\mathrm{Th}}$ was then confirmed only if the $\mathrm{RMS}_{\mathrm{EMG}}$ plot rose and stayed above the confidence limit (e.g., Fig.1), without descending back to within the confidence interval until the end of the test (e.g., Fig.2). For those participants showing a threshold, the power output at the $\mathrm{EMG}_{\mathrm{Th}}$ time point was determined. This power output was expressed as a percentage of the peak power output reached during the $\mathrm{EMG}_{\mathrm{Th}}$ test $\left(\% \mathrm{P}_{\mathrm{max}}\right)$ and as a percentage of $\mathrm{VO}_{2} \mathrm{pk}$ $\left(\% \mathrm{VO}_{2} \mathrm{pk}\right)$, based on the data obtained from the first session's $\mathrm{VO}_{2}$ testing.

[Figure 2]

\section{Statistical Analysis}

All statistical analysis was performed using SPSS v.20 (SPSS Inc., Chicago, IL). The data for all groups are presented as means $\pm 1 \mathrm{SD}$. All data were normally distributed. Group differences in physical characteristics and $\% \mathrm{P}_{\max }$ and $\% \mathrm{VO}_{2} \mathrm{pk}$ at $\mathrm{EMG}_{\mathrm{Th}}$ were assessed using a two-tailed, homoscedastic Student's t-test. Additionally, group differences between 'Responders' and 'Non-Responders' (see Results section) were examined using a two-tailed Student's t-test. Despite the small sample size, assumptions for normal distribution and homogeneity of variance were met. Pearson's Correlations were computed for the boys, men, and the combined groups, between the $\mathrm{EMG}_{\mathrm{Th}}$ (both as $\% \mathrm{VO}_{2} \mathrm{pk}$ and $\% \mathrm{P}_{\max }$ ) and $\mathrm{VO}_{2} \mathrm{pk} \cdot \mathrm{kgBW}^{-1}, \mathrm{PVO}_{2} \mathrm{pk} \cdot \mathrm{kgBW}^{-1}$, $\mathrm{P}_{\max } \cdot \mathrm{kgBW}^{-1}$, leisure time physical activity, and training hours per week, respectively. The acceptable level of significance for all tests was set at $p<0.05$.

\section{Results}

Physical activity scores and training histories were similar in the two groups (Table 1). Importantly, peak heart rate was, on average, 4 bpm higher in the boys whose $\mathrm{VO}_{2}$ pk was also 
marginally higher. While none of these differences reached statistical significance they do strongly suggest that the boys had attained a comparable level of exertion to that of the men.

An $\mathrm{EMG}_{\mathrm{Th}}$ was identified in 20 out of the 21 men (95.2\%) and in 18 of 23 boys (78.3\%) $\left(\chi_{(1, \mathrm{n}=44)}^{2}=2.69, p=0.10\right)$. In the participants for whom a threshold was identified, group differences showed $6.6 \%$ higher (later) $\mathrm{EMG}_{\mathrm{Th}} \% \mathrm{P}_{\max }$ in the boys compared with the men $\left(\mathrm{t}_{(36)}=-2.08, p=0.045\right)(86.4 \pm 9.6 \%$ vs. $79.7 \pm 10.0 \%$, respectively; Fig.3). There was also a trend for a higher $\mathrm{EMG}_{\mathrm{Th}} \% \mathrm{VO}_{2}$ pk in the boys $v s$. men $\left(\mathrm{t}_{(35)}=-1.62, p=0.12\right)(101.2 \pm 11.4 v s$. $94.8 \pm 12.2 \%$, respectively; Fig.3) (only 17 boys included. $\mathrm{VO}_{2}$ data could not be obtained for one boy).

[Figure 3]

Correlational analyses revealed that for all participants, $\mathrm{EMG}_{\mathrm{Th}}\left(\% \mathrm{VO}_{2} \mathrm{pk}\right)$ was not correlated with body-mass-normalized $\mathrm{VO}_{2} \mathrm{pk}\left(\mathrm{VO}_{2} \mathrm{pk} \cdot \mathrm{kg}^{-1}\right)(r=-0.18, p>0.05)$. However, when examined separately for each group, a significant negative correlation was observed in the boys $(r=-0.51, p=0.015)$, but not in the men $(\mathrm{r}=0.18, \mathrm{p}>0.05)$. Also, $\mathrm{EMG}_{\mathrm{Th}}\left(\% \mathrm{VO}_{2} \mathrm{pk}\right)$ similarly correlated with the power output at $\mathrm{VO}_{2} \mathrm{pk} \cdot \mathrm{kg}^{-1}\left(\mathrm{PVO}_{2} \mathrm{pk} \cdot \mathrm{kg}^{-1}\right)$ in the boys $(r=-0.52, p=0.03)$ (Fig.4), but not in the men. No significant correlations were found between $\mathrm{EMG}_{\mathrm{Th}} \% \mathrm{P}_{\max }$ or $\mathrm{EMG}_{\mathrm{Th}} \% \mathrm{VO}_{2} \mathrm{pk}$ and training history, or leisure time physical activity.

[Figure 4]

For further analysis, the boys who demonstrated $\mathrm{EMG}_{\mathrm{Th}}$ ('Responders', $\mathrm{n}=18$ ) were compared to those who did not ('Non-responders', $n=5$ ) (Table 2). The 'Responders' had significantly longer mean test duration than the 'Non-responders' $(\mathrm{p}=0.016)$ as well as 
significantly greater $\mathrm{Pmax} / \mathrm{PVO}_{2} \mathrm{pk}$ ratio $(\mathrm{p}=0.027)$. There were no statistically significant differences in any other variables.

In the men's group, only one participant did not show an $\mathrm{EMG}_{\mathrm{Th}}$. He had exceptionally-high $\mathrm{VO}_{2} \mathrm{pk} \cdot \mathrm{kg}^{-1}$ and $\mathrm{PVO}_{2} \mathrm{pk} \cdot \mathrm{kg}^{-1}$ values that were $\sim 2.5 \mathrm{SDs}$ above the group's mean.

[Table 2]

\section{Discussion}

The main findings of this study are that a) $\mathrm{EMG}_{\mathrm{Th}}$ was identified in only $78.3 \%(18 / 23)$ of the boys, while the corresponding value in the men was 95.2\% (20/21); and b) Among those in whom $\mathrm{EMG}_{\mathrm{Th}}$ was detected, the boys' $\mathrm{EMG}_{\mathrm{Th}}$ occurred at significantly higher relative workloads compared with the men. As the $\mathrm{EMG}_{\mathrm{Th}}$ is widely believed to reflect the onset of accelerated increase in higher-threshold, type-II MU recruitment during progressive exercise (Edwards and Lippold 1956; Hug et al. 2006b; Hug et al. 2003; Lucia et al. 1999; Maestu et al. 2006; Moritani and deVries 1978; Moritani et al. 1993; Moritani et al. 1984; Nagata et al. 1981; Petrofsky 1979; Tikkanen et al. 2012), these findings suggest that boys activate their type-II MUs later and for a shorter duration than do men.

The results for our men's group are in close agreement with previous findings (Hug et al. 2006b; Lucia et al. 1999; Takaishi et al. 1992). However, to our knowledge, this is the first study to investigate the $\mathrm{EMG}_{\mathrm{Th}}$ in children. Compared with the men, our boys' higher relative $\mathrm{EMG}_{\mathrm{Th}}$ is in line with our hypothesis, based on known boys-men differences in $\mathrm{La}_{\mathrm{Th}}$ and $\mathrm{Ve}_{\mathrm{Th}}$. Our observed differences of $6.6 \% \mathrm{P}_{\max }$ and $6.4 \% \mathrm{VO}_{2} \mathrm{pk}$ are similar to previously reported boys-men $\% \mathrm{VO}_{2}$ pk differences in $\mathrm{Ve}_{\mathrm{Th}}$ [7.2\%, (Klentrou et al. 2006); 8.9\%, (Anderson and Mahon 2007)] and $\mathrm{La}_{\mathrm{Th}}[9.1 \%$, (Anderson and Mahon 2007)] during cycling exercise. 
A question arising from our findings is why $\mathrm{EMG}_{\mathrm{Th}}$ could not be detected in the five 'Nonresponder' boys? At exhaustion, the force applied by the participating muscles is considerably lower than MVC for the given pedalling cadence (Greig et al. 1985; Sargeant et al. 1981). In view of the fact that $50 \%$ of 'Responders' $\mathrm{EMG}_{\mathrm{Th}}$ occurred very close to exhaustion ( $>92 \%$ Pmax), it is conceivable that the five 'Non-Responders' terminated their tests before attaining the force level at which $\mathrm{EMG}_{\mathrm{Th}}$ would have taken place. That is, had they been able to continue exercising longer, their $\mathrm{EMG}_{\mathrm{Th}}$ would have occurred at their observed power at exhaustion or above it. This suggestion is supported by our finding that, in the 'Responders', body-massnormalized peak aerobic power $\left(\mathrm{PVO}_{2} \mathrm{pk} / \mathrm{kg}\right)$ negatively correlated with $\mathrm{EMG}_{\mathrm{Th}} \% \mathrm{VO}_{2} \mathrm{pk}$ $\left(\mathrm{r}=-0.52\right.$, $\mathrm{p}=0.03$; Fig.4). That is, in boys with lower maximal power output, $\mathrm{EMG}_{\mathrm{Th}}$ was attained closer to maximal aerobic power, compared with more powerful boys. This, in turn, suggests that 'Non-responders' may not have been able to produce the power and thus the contractile force required to manifest the $\mathrm{EMG}_{\mathrm{Th}}$. Further support for the suggestion is provided by Vollestad \& Blom (Vollestad and Blom 1985; Vollestad et al. 1984) who found that activation of type $\mathrm{II}_{\mathrm{AX}}\left(\mathrm{II}_{\mathrm{AB}}\right)$ and $\mathrm{II}_{\mathrm{X}}\left(\mathrm{II}_{\mathrm{B}}\right)$ MUs in adult men, during progressive cycling, took place only at $91 \% \mathrm{VO}_{2} \mathrm{pk}$ and beyond. As shown by Greig et al. (Greig et al. 1985), this power output level would require only $\sim 50 \%$ of the maximal pedal force at that cadence.

Accepting the notion that $\mathrm{EMG}_{\mathrm{Th}}$ could indeed occur at or above the peak force level attained in progressive exercise to exhaustion, means that $\mathrm{EMG}_{\mathrm{Th}}$ would only be detected in those individuals able to exceed the critical force by the end of the progressive exercise test. It is conceivable then that 'Non-Responders' ended their tests prior to attaining the sufficiently high power output necessary to attain that critical force and elicit $\mathrm{EMG}_{\mathrm{Th}}$. Men attain higher relative force and power outputs due to their higher anaerobic capacity compared with the boys (Beneke 
et al. 2007; Van Praagh and Dore 2002). Thus, most men produce the muscle force necessary for $\mathrm{EMG}_{\mathrm{Th}}$ manifestation. For this reason, there was little or no correlation between $\mathrm{EMG}_{\mathrm{Th}}$ and $\mathrm{VO}_{2}$ pk or $\mathrm{PVO}_{2} \mathrm{pk}$ in the men, unlike in the boys. Support for this notion comes from the fact that compared with 'Non-Responders', 'Responders' had significantly longer test durations and higher Pmax $/ \mathrm{PVO}_{2}$ pk ratio (Table 2). That is, 'Responders' were able to employ more anaerobic power after reaching their respective $\mathrm{PVO}_{2} \mathrm{pk}$ and thus extend their test durations. Presumably, this was facilitated by the 'Responders' greater relative capacity to recruit type-II MUs.

The boys-men difference of $6.6 \%$ in $\mathrm{EMG}_{\mathrm{Th}} \% \mathrm{Pmax}$ (boys=86.4\%, $\left.\operatorname{men}=79.4 \% ; \mathrm{p}=0.045\right)$ is likely an underestimate of group difference as it reflects only the 'Responders'. Assigning just $100 \%$ as the $\mathrm{EMG}_{\mathrm{Th}} \% \mathrm{Pmax}$ values for the six 'Non-Responders' (5 boys, $1 \mathrm{man}$ ), the overall boys - men $\mathrm{EMG}_{\mathrm{Th}}$ difference increased by $30 \%$ to $8.6 \%$ (boys $=89.3$, men=80.7\%; $\mathrm{p}<0.01$ ). Accepting the possibility that $\mathrm{EMG}_{\mathrm{Th}}$ could occur at $>100 \%$ Pmax intensity, the true boys-men difference could well be even larger.

To illuminate possible underlying distinguishing factors, the 'Responder' and 'Nonresponder' boys were compared (Table 2). On average, 'Responders' lasted $18 \%$ longer in their respective $\mathrm{EMG}_{\mathrm{Th}}$ tests than did 'Non-responders'. Accordingly, their final power output (Pmax) was $15.5 \%$ higher, although this difference did not reach statistical significance. Since initial loading and the ramping protocol of the $\mathrm{EMG}_{\mathrm{Th}}$ test were based on peak aerobic power $\left(\mathrm{PVO}_{2} \mathrm{pk}\right),>95 \%$ of participants attained a Pmax that was greater than $\mathrm{PVO}_{2} \mathrm{pk}$. However, while the 'Responders' Pmax was 17\% higher, 'Non-responders' Pmax was only 5\% higher than $\mathrm{PVO}_{2} \mathrm{pk}(\mathrm{p}<0.03)$. Again, this suggests that 'Non-responders' were less capable of recruiting the higher-threshold type-II MUs and generating the extra anaerobic power necessary to exceed $\mathrm{PVO}_{2} \mathrm{pk}$. The 'Non-responders' tended to be younger, lighter, and shorter; have lower lean body 
mass, be less physically active, and somatically less mature (longer time before PHV). Although none of these differences was statistically significant, the general picture is one of lower maturity level, which may be regarded as consistent with them possessing higher or no detectable $\mathrm{EMG}_{\mathrm{Th}}$.

The only man in whom $\mathrm{EMG}_{\mathrm{Th}}$ could not be detected, had the highest $\mathrm{VO}_{2} \mathrm{pk}\left(63.6 \mathrm{ml} \cdot \mathrm{kg}^{-}\right.$ $\left.{ }^{1} \cdot \mathrm{min}^{-1}\right)$ and $\mathrm{PVO}_{2} \mathrm{pk}\left(5.14 \mathrm{~W} \cdot \mathrm{kg}^{-1}\right)$, both of which were $\sim 2.5 \mathrm{SD}$ above the mean for the group. Since in comparable studies (e.g., (Hug et al. 2006a, b; Hug et al. 2003) the $\mathrm{EMG}_{\mathrm{Th}}$ was detected in $100 \%$ of participants, we suggest that the absence of $\mathrm{EMG}_{\mathrm{Th}}$ in this individual was not due to error and that his high aerobic capacity could have been due to particularly high type-I musclefibre composition. Thus, like the boy 'Non-Responders', he too might not have been able to sufficiently engage type-II MUs by the time he reached exhaustion.

Given the previously demonstrated relationships between $\mathrm{EMG}_{\mathrm{Th}}$ and both $\mathrm{La}_{\mathrm{Th}}$ and $\mathrm{Ve}_{\mathrm{Th}}$ in men (Candotti et al. 2008; Chwalbinska-Moneta et al. 1998; Moritani et al. 1993; Moritani et al. 1984; Nagata et al. 1981; Tikkanen et al. 2012), similar relationships presumably exist in boys, as well. In both men and boys, however, there is a persistent difference between exercise intensity at $\mathrm{La}_{\mathrm{Th}}$ or $\mathrm{Ve}_{\mathrm{Th}} v s$. that of $\mathrm{EMG}_{\mathrm{Th}}$. For example, in men, $\mathrm{La}_{\mathrm{Th}}$ and $\mathrm{Ve}_{\mathrm{Th}}$ have been typically found between $\sim 50-60 \% \mathrm{VO}_{2}$ pk (Anderson and Mahon 2007; Klentrou et al. 2006; Simon et al. 1986), while $\mathrm{EMG}_{\mathrm{Th}}$ has been identified at $\sim 90 \% \mathrm{VO}_{2}$ pk (Lucia et al. 1999; Takaishi et al. 1992) and at $94.8 \% \mathrm{VO}_{2} \mathrm{pk}$ in the present study. The corresponding values for boys are $\sim 60-70 \% \mathrm{VO}_{2}$ pk for $\mathrm{La}_{\mathrm{Th}} \& \mathrm{Ve}_{\mathrm{Th}}$ (Anderson and Mahon 2007; Klentrou et al. 2006) and $101.2 \% \mathrm{VO}_{2} \mathrm{pk}$ for $\mathrm{EMG}_{\mathrm{Th}}$ (in the present study). While boys' values are generally $\sim 10 \%$ higher than the men's, the differences between the $\mathrm{EMG}_{\mathrm{Th}}$ and the $\mathrm{La}_{\mathrm{Th}}$ or $\mathrm{Ve}_{\mathrm{Th}}$ thresholds are rather similar: $\sim 45 \%$ in both groups. A notable exception to this pattern is Candotti et al.'s finding of nearly identical $\mathrm{EMG}_{\mathrm{Th}}$ and $\mathrm{La}_{\mathrm{Th}}$ values in adult recreational cyclists (Candotti et al. 
2008). A partial explanation for this discrepancy is the $\mathrm{La}_{\mathrm{Th}}$ protocol used by Candotti et al.

(continuous, 3-min stages), which overestimates $\mathrm{La}_{\mathrm{Th}}$ due to the delay in the lactate response to the fast changing workloads. Furthermore, the testing protocol was exhaustion-limited at $\sim 200 \mathrm{~W}$, likely due to lactate accumulation and well before $\mathrm{VO}_{2} \mathrm{pk}$ or $\mathrm{PVO}_{2} \mathrm{pk}$ could be reached. Thus, the mean reported $\mathrm{EMG}_{\mathrm{Th}}(134 \mathrm{~W})$ occurred at no more than $\sim 67 \%$ of the end-of-protocol power and in reality likely constituted $\mathrm{VO}_{2}$ pk percentage considerably lower than that. Since Hug et al. detected two rather than a single $\mathrm{EMG}_{\mathrm{Th}}$ in professional cyclists (at 52 and $86 \% \mathrm{VO}_{2} \mathrm{pk}$ ) (Hug et al. 2003), it is conceivable that the $\mathrm{EMG}_{\mathrm{Th}}$ reported by Candotti et al. (Candotti et al. 2008) is the first (lower) rather than the second of the two thresholds.

The typical magnitude of the $\mathrm{EMG}_{\mathrm{Th}}-\mathrm{La}_{\mathrm{Th}}$ difference appears to suggest that the $\mathrm{EMG}_{\mathrm{Th}}$ phenomenon is independent of the factors governing $\mathrm{La}_{\mathrm{Th}}$ and $\mathrm{Ve}_{\mathrm{Th}}$, but the apparent consistency of this difference in men and boys seems to suggest otherwise. Several factors should be considered in explaining the apparent $\mathrm{EMG}_{\mathrm{Th}}-\mathrm{La}_{\mathrm{Th}} / \mathrm{Ve}_{\mathrm{Th}}$ discrepancy: a. While $\mathrm{La}_{\mathrm{Th}}$ and $\mathrm{Ve}_{\mathrm{Th}}$ are systemic, whole-body phenomena, the $\mathrm{EMG}_{\mathrm{Th}}$ is confined to a single-muscle. $\mathbf{b}$. The metabolic acidosis and increased lactate production that underlie both $\mathrm{La}_{\mathrm{Th}}$ and $\mathrm{Ve}_{\mathrm{Th}}$, take place as a function of increasing exercise intensity in the active MUs and could occur regardless of whether or not higher-threshold MUs are involved. $\mathrm{EMG}_{\mathrm{Th}}$, on the other hand, is presumably dependent on type-II MU involvement and could thus occur considerably after $\mathrm{La}_{\mathrm{Th}}$ or $\mathrm{Ve}_{\mathrm{Th}}$ have already taken place. c. Based on evidence such as Vollestad \& Blom's glycogen depletion findings (Vollestad and Blom 1985), $\mathrm{La}_{\mathrm{Th}}$ and $\mathrm{Ve}_{\mathrm{Th}}$ could be related to increased type- $\mathrm{II}_{\mathrm{A}} \mathrm{MU}$ recruitment, which occurs at low or moderate intensities. The $\mathrm{EMG}_{\mathrm{Th}}$, on the other hand, might be associated with recruitment of the fast-twitch MU types $\mathrm{II}_{\mathrm{AX}}\left(\mathrm{II}_{\mathrm{AB}}\right)$ and $\mathrm{IIx}\left(\mathrm{II}_{\mathrm{B}}\right)$, which typically occurs in the later part of exhaustive exercise. 
It may be of interest to draw an analogy between children and elite adult endurance athletes. Compared with untrained men, boys are characterized by markedly higher thresholds of all 3 types $\left(\mathrm{La}_{\mathrm{Th}}, \mathrm{Ve}_{\mathrm{Th}}, \mathrm{EMG}_{\mathrm{Th}}\right)$. The same has been shown to be true for endurance athletes, in whom the higher thresholds are attained by extensive training at moderate intensities that, according to the size principle (Henneman et al. 1965) and glycogen depletion data (Vollestad and Blom 1985; Vollestad et al. 1984), predominantly recruit type-I and possibly the lower portion of the type- $\mathrm{II}_{\mathrm{A}} \mathrm{MU}$ pool. Also, such athletes often possess higher type-I MU composition to begin with (Costill et al. 1976). Consequently, adult endurance athletes utilize type-I MUs to a greater extent than do non-athletes. The present data indicate that children (boys) are characterized by lower utilization of type-II MUs and thus, greater reliance on type-I MUs utilization as is the case in endurance athletes. The difference is that in children this is not due to training or talent, but rather to what we suggest is their lower utilization of type-II MUs.

\section{Conclusions}

Our findings suggest that the fundamental nature of MU recruitment in progressive exercise [Henneman's size principle; (Henneman et al. 1965)] is qualitatively similar in boys and men. There is, however, a significant quantitative difference in that the boys' $\mathrm{EMG}_{\mathrm{Th}}$ occurred at higher exercise intensities compared with the men's. This age-related difference suggests later recruitment of higher threshold MUs in boys and is in line with previous findings of higher relative $\mathrm{La}_{\mathrm{Th}}$ and $\mathrm{Ve}_{\mathrm{Th}}$ in boys compared with men. These findings support the child-adult differential MU-activation hypothesis. We suggest that this support is particularly insightful since the $\mathrm{EMG}_{\mathrm{Th}}$ is currently the best non-invasive 'window' into the type of differential MU activation at the core of the hypothesis. 


\section{Acknowledgements}

The authors wish to thank all participants for the hard work and dedication they invested in this study. We are also indebted to the boys' parents or guardians for consenting, bringing the boys, and making it all possible. Special gratitude and appreciation is reserved for Mr. James Desjardins for developing the necessary software in a most proficient manner and with the utmost patience for the whims and wishes of the researchers. 


\section{References}

Anderson CS, Mahon AD (2007) The relationship between ventilatory and lactate thresholds in boys and men. Res Sports Med 15: 189-200

Bearden SE, Moffatt RJ (2001) Leg electromyography and the VO2-power relationship during bicycle ergometry. Med Sci Sports Exerc 33: 1241-1245

Beneke R, Hutler M, Leithauser RM (2007) Anaerobic performance and metabolism in boys and male adolescents. Eur J Appl Physiol 101: 671-677

Blimkie CJ (1989) Age- and sex-associated variation in strength during childhood:

Anthropometric, morphologic, neurologic, biomechanical, endocrinologic, genetic, and physical activity correlates. In: Gisolfi CV (ed) Perspectives in Exercise Science and Sports Medicine, Vol 2: Youth, Exercise and Sports. Benchmark Press, Indianapolis, IN, pp. 99163

Candotti CT, Loss JF, Melo Mde O, La Torre M, Pasini M, Dutra LA, de Oliveira JL, de Oliveira LP (2008) Comparing the lactate and EMG thresholds of recreational cyclists during incremental pedaling exercise. Can J Physiol Pharmacol 86: 272-278

Chwalbinska-Moneta J, Hanninen O, Penttila I (1994) Relationships between EMG and blood lactate accumulation during incremental exercise in endurance- and speed-trained athletes. Clin J Sports Med 4: 31-38

Chwalbinska-Moneta J, Kaciuba-Uscilko H, Krysztofiak H, Ziemba A, Krzeminski K, Kruk B, Nazar K (1998) Relationship between EMG blood lactate, and plasma catecholamine thresholds during graded exercise in men. J Physiol Pharmacol 49: 433-441

Costill DL, Fink WJ, Pollock ML (1976) Muscle fiber composition and enzyme activities of elite distance runners. Med Sci Sports 8: 96-100

Dotan R, Mitchell C, Cohen R, Klentrou P, Gabriel D, Falk B (2012) Child-adult differences in muscle activation - a review. Pediatr Exerc Sci 24: 2-21

Edwards RG, Lippold OC (1956) The relation between force and integrated electrical activity in fatigued muscle. The Journal of physiology 132: 677-681 
Falk B, Usselman C, Dotan R, Brunton L, Klentrou P, Shaw J, Gabriel D (2009) Child-adult differences in muscle strength and activation pattern during isometric elbow flexion and extension. Appl Physiol Nutr Metab 34: 609-615

Farina D, Macaluso A, Ferguson RA, De Vito G (2004) Effect of power, pedal rate, and force on average muscle fiber conduction velocity during cycling. J Appl Physiol (1985) 97: 20352041

Godin G, Shephard RJ (1985) A simple method to assess exercise behavior in the community. Can J Appl Sport Sci 10: 141-146

Greig C, Sargeant AJ, Vollestad NK (1985) Muscle force and fibre recruitment during dynamic exercise in man. J Physiol London 371: 176P

Halin R, Germain P, Bercier S, Kapitaniak B, Buttelli O (2003) Neuromuscular response of young boys versus men during sustained maximal contraction. Med Sci Sports Exerc 35: $1042-1048$

Henneman E, Somjen G, Carpenter DO (1965) Functional Significance of Cell Size in Spinal Motoneurons. J Neurophysiol 28: 560-580

Hug F, Decherchi P, Marqueste T, Jammes Y (2004) EMG versus oxygen uptake during cycling exercise in trained and untrained subjects. J Electromyogr Kinesiol 14: 187-195

Hug F, Laplaud D, Lucia A, Grelot L (2006a) A comparison of visual and mathematical detection of the electromyographic threshold during incremental pedaling exercise: a pilot study. Journal of strength and conditioning research / National Strength \& Conditioning Association 20: 704-708

Hug F, Laplaud D, Lucia A, Grelot L (2006b) EMG threshold determination in eight lower limb muscles during cycling exercise: a pilot study. Int J Sports Med 27: 456-462

Hug F, Laplaud D, Savin B, Grelot L (2003) Occurrence of electromyographic and ventilatory thresholds in professional road cyclists. Eur J Appl Physiol 90: 643-646

Klentrou N, Nishio M-L, Plyley M (2006) Ventilatory breakpoints in boys and men. Pediatr Exerc Sci 18: 216-225 
Lucia A, Sanchez O, Carvajal A, Chicharro JL (1999) Analysis of the aerobic-anaerobic transition in elite cyclists during incremental exercise with the use of electromyography. $\mathrm{Br}$ J Sports Med 33: 178-185

Maestu J, Cicchella A, Purge P, Ruosi S, Jurimae J, Jurimae T (2006) Electromyographic and neuromuscular fatigue thresholds as concepts of fatigue. Journal of strength and conditioning research / National Strength \& Conditioning Association 20: 824-828

Mirwald RL, Baxter-Jones AD, Bailey DA, Beunen GP (2002) An assessment of maturity from anthropometric measurements. Med Sci Sports Exerc 34: 689-694

Miyashita M, Kanehisa H (1980) Correlation between efficiency in cycling and maximal power of human extensor muscles. J Sports Med Phys Fitness 20: 365-370

Moritani T, deVries HA (1978) Reexamination of the relationship between the surface integrated electromyogram (IEMG) and force of isometric contraction. Am J Phys Med 57: 263-277

Moritani T, Takaishi T, Matsumoto T (1993) Determination of maximal power output at neuromuscular fatigue threshold. J Appl Physiol (1985) 74: 1729-1734

Moritani T, Tanaka H, Yoshida T, Ishii C, Yoshida T, Shindo M (1984) Relationship between myoelectric signals and blood lactate during incremental forearm exercise. Am J Phys Med 63: $122-132$

Nagata A, Muro M, Moritani T, Yoshida T (1981) Anaerobic threshold determination by blood lactate and myoelectric signals. Jpn J Physiol 31: 585-597

O'Brien TD, Reeves ND, Baltzopoulos V, Jones DA, Maganaris CN (2009) The effects of agonist and antagonist muscle activation on the knee extension moment-angle relationship in adults and children. Eur J Appl Physiol 106: 849-856

O'Brien TD, Reeves ND, Baltzopoulos V, Jones DA, Maganaris CN (2010) In vivo measurements of muscle specific tension in adults and children. Exp Physiol 95: 202-210

Petrofsky JS (1979) Frequency and amplitude analysis of the EMG during exercise on the bicycle ergometer. Eur J Appl Physiol Occup Physiol 41: 1-15

Ryan MM, Gregor RJ (1992) EMG profiles of lower extremity muscles during cycling at constant workload and cadence. J Electromyogr Kinesiol 2: 69-80 
Sargeant AJ, Hoinville E, Young A (1981) Maximum leg force and power output during shortterm dynamic exercise. J Appl Physiol Respir Environ Exerc Physiol 51: 1175-1182

Simon G, Berg A, Simon-Alt A, Keul J (1981) Determination of the anaerobic threshold depending on age and performance potential. Dtsch Z Sportsmed 32: 7-14

Simon J, Young JL, Blood DK, Segal KR, Case RB, Gutin B (1986) Plasma lactate and ventilation thresholds in trained and untrained cyclists. J Appl Physiol (1985) 60: 777-781

Slaughter MH, Lohman, T. G., Boileau, B.A. (1988) Skinfold equations for estimation of body fatness in children and youth. Hum Biol 60: 709-723

Takaishi T, Ono T, Yasuda Y (1992) Relationship between muscle fatigue and oxygen uptake during cycle ergometer exercise with different ramp slope increments. Eur J Appl Physiol Occup Physiol 65: 335-339

Tanaka H, Shindo M (1985) Running velocity at blood lactate threshold of boys aged 6-15 years compared with untrained and trained young males. Int J Sports Med 6: 90-94

Tanner JM (1962) Growth at Adolescence. Blackwell Scientific Publications, Oxford

Taylor AD, Bronks R (1994) Electromyographic correlates of the transition from aerobic to anaerobic metabolism in treadmill running. Eur J Appl Physiol Occup Physiol 69: 508-515

Tikkanen O, Hu M, Vilavuo T, Tolvanen P, Cheng S, Finni T (2012) Ventilatory threshold during incremental running can be estimated using EMG shorts. Physiol Meas 33: 603-614

Van Praagh E, Dore E (2002) Short-term muscle power during growth and maturation. Sports Med 32: 701-728

Viitasalo JT, Luhtanen P, Rahkila P, Rusko H (1985) Electromyographic activity related to aerobic and anaerobic threshold in ergometer bicycling. Acta Physiol Scand 124: 287-293

Vollestad NK, Blom PC (1985) Effect of varying exercise intensity on glycogen depletion in human muscle fibres. Acta Physiol Scand 125: 395-405

Vollestad NK, Vaage O, Hermansen L (1984) Muscle glycogen depletion patterns in type I and subgroups of type II fibres during prolonged severe exercise in man. Acta Physiol Scand 122: $433-441$ 


\section{Acknowledgements}

The authors are grateful to all of the participants and the boys' parents for the time, best efforts, and the dedication they invested in making this study possible. Special thanks to Colin Russell, Makis Papadopoulos, and Orian Falk-Dotan for serving as 'guinea pigs' in our pilot studies prior to serving as participants in the present study. We are particularly indebted to $\mathrm{Mr}$. James Desjardins for his professionalism and the invaluable work and advice in developing the analytical software tools for this study.

\section{Funding}

The study was funded by the Canadian Institutes of Health Research, grant \#199944

\section{Competing Interests}

The authors have no competing interests to declare. 


\section{Figure Legends}

Figure 1. A representative $\mathrm{RMS}_{\mathrm{EMG}}$ trace of an adult man participant. Note the clear rise of the trace above the $+3 \mathrm{SD}$ confidence interval.

Figure 2. A representative $\mathrm{RMS}_{\mathrm{EMG}}$ trace of a boy participant. No $\mathrm{EMG}_{\mathrm{Th}}$ is identifiable in this trace.

Figure 3. Group differences in relative exercise intensity at the $\mathrm{EMG}_{\mathrm{Th}}$ between boys and men in whom $\mathrm{EMG}_{\mathrm{Th}}$ was identified ('Responders'). Values are Mean $\pm 1 \mathrm{SD}$.

$*$ = boys significantly higher than men, $\mathrm{p}<0.05$.

Figure 4. Correlation between peak aerobic power $\left(\mathrm{PVO}_{2} \mathrm{pk}\right)$ and $\mathrm{EMG}_{\mathrm{Th}}$ as $\% \mathrm{VO} 2 \mathrm{pk}$ for the boys who showed $\mathrm{EMG}_{\mathrm{Th}}\left(\mathrm{n}=17 ; \mathrm{VO}_{2}\right.$ data unavailable for one boy). 


\section{Tables}

Table 1. Participants' physical characteristics and training histories. Values are Means $\pm 1 \mathrm{SD}$.

\begin{tabular}{|l|c|c|}
\cline { 2 - 3 } \multicolumn{1}{c|}{} & Men & Boys \\
\hline $\mathrm{n}$ & 21 & 23 \\
\hline Age $(\mathrm{y})$ & $23.4 \pm 4.1$ & $11.1 \pm 1.1^{*}$ \\
\hline Mass $(\mathrm{kg})$ & $75.4 \pm 10.4$ & $37.1 \pm 7.5^{*}$ \\
\hline Height $(\mathrm{cm})$ & $181.5 \pm 6.3$ & $145.7 \pm 8.6^{*}$ \\
\hline \%Fat & $14.0 \pm 3.6$ & $14.2 \pm 3.2$ \\
\hline Activity Score & $79.1 \pm 50.9$ & $81.6 \pm 25.3$ \\
\hline Sport training $\left(\mathrm{hours}^{\circ} \mathrm{week}^{-1}\right)$ & $5.6 \pm 4.8$ & $5.4 \pm 2.6$ \\
\hline VO 2 pk $\left(\mathrm{ml} \cdot \mathrm{kg} \cdot \mathrm{min}^{-1}\right)$ & $49.7 \pm 5.5$ & $50.1 \pm 7.4$ \\
\hline RER at $\mathrm{VO}_{2} \mathrm{pk}$ & $1.15 \pm 0.06$ & $1.05 \pm 0.08^{*} \#$ \\
\hline HR at $\mathrm{VO}_{2} \mathrm{pk}(\mathrm{bpm})$ & $194 \pm 7$ & $198 \pm 11$ \\
\hline
\end{tabular}

* - Significant difference between groups, $\mathrm{p}<0.05$

$\#-\mathrm{n}=22\left(\mathrm{VO}_{2}\right.$ data unavailable for one boy) 
Table 2. Comparison between $\mathrm{EMG}_{\mathrm{Th}}$ 'Responders' and 'Non-Responders' among the boys. Values are Means \pm 1 SD.

\begin{tabular}{|c|c|c|}
\hline & 'Responders' & 'Non-Responders' \\
\hline $\mathrm{n}$ & 18 & 5 \\
\hline Age, years & $11.1 \pm 1.2$ & $11.1 \pm 0.8$ \\
\hline Years to age of PHV & $2.26 \pm 0.68$ & $2.52 \pm 0.32$ \\
\hline Body mass, kg & $38.0 \pm 7.9$ & $34.0 \pm 5.0$ \\
\hline Height, cm & $146.8 \pm 9.0$ & $141.7 \pm 6.4$ \\
\hline Lean Body Mass, kg & $32.4 \pm 6.2$ & $29.2 \pm 3.8$ \\
\hline Activity score & $83.5 \pm 27.3$ & $74.9 \pm 16.9$ \\
\hline $\mathrm{VO}_{2} \mathrm{pk}, \mathrm{ml} \cdot \mathrm{kg}^{-1} \cdot \mathrm{min}^{-1}$ & $50.5 \pm 7.8$ & $48.9 \pm 6.1$ \\
\hline $\mathrm{EMG}_{\mathrm{Th}}$ test duration, $\mathrm{s}$ & $598 \pm 65$ & $507 \pm 67 *$ \\
\hline $\mathrm{Pmax} / \mathrm{kg}, \mathrm{W} \cdot \mathrm{kg}^{-1}$ & $4.02 \pm 0.65$ & $3.88 \pm 0.43$ \\
\hline $\mathrm{Pmax} / \mathrm{PVO}_{2} \mathrm{pk}$ ratio & $1.17 \pm 0.09$ & $1.05 \pm 0.09 *$ \\
\hline
\end{tabular}

$*$ = Significant difference between groups; $p<0.05$ 


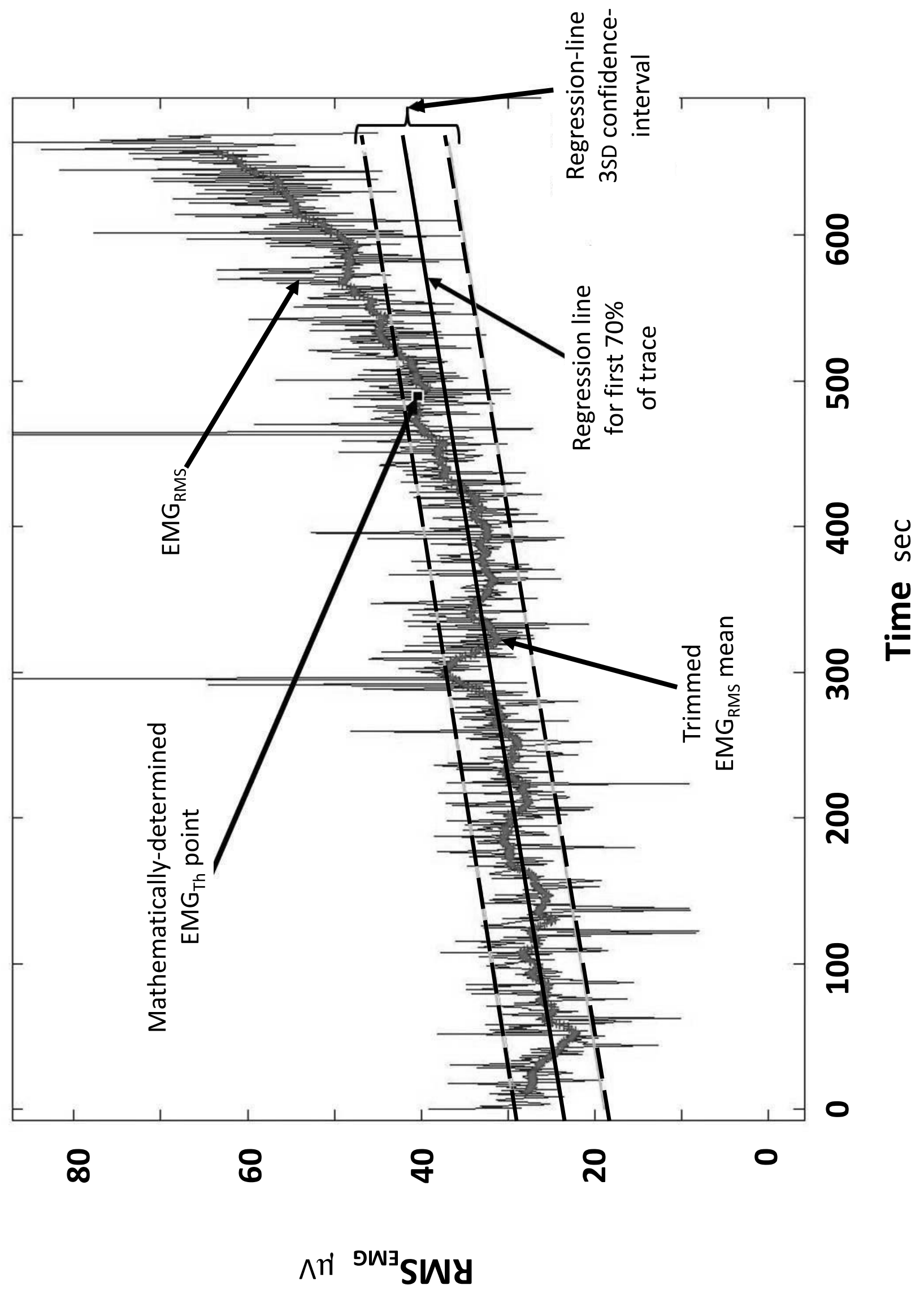




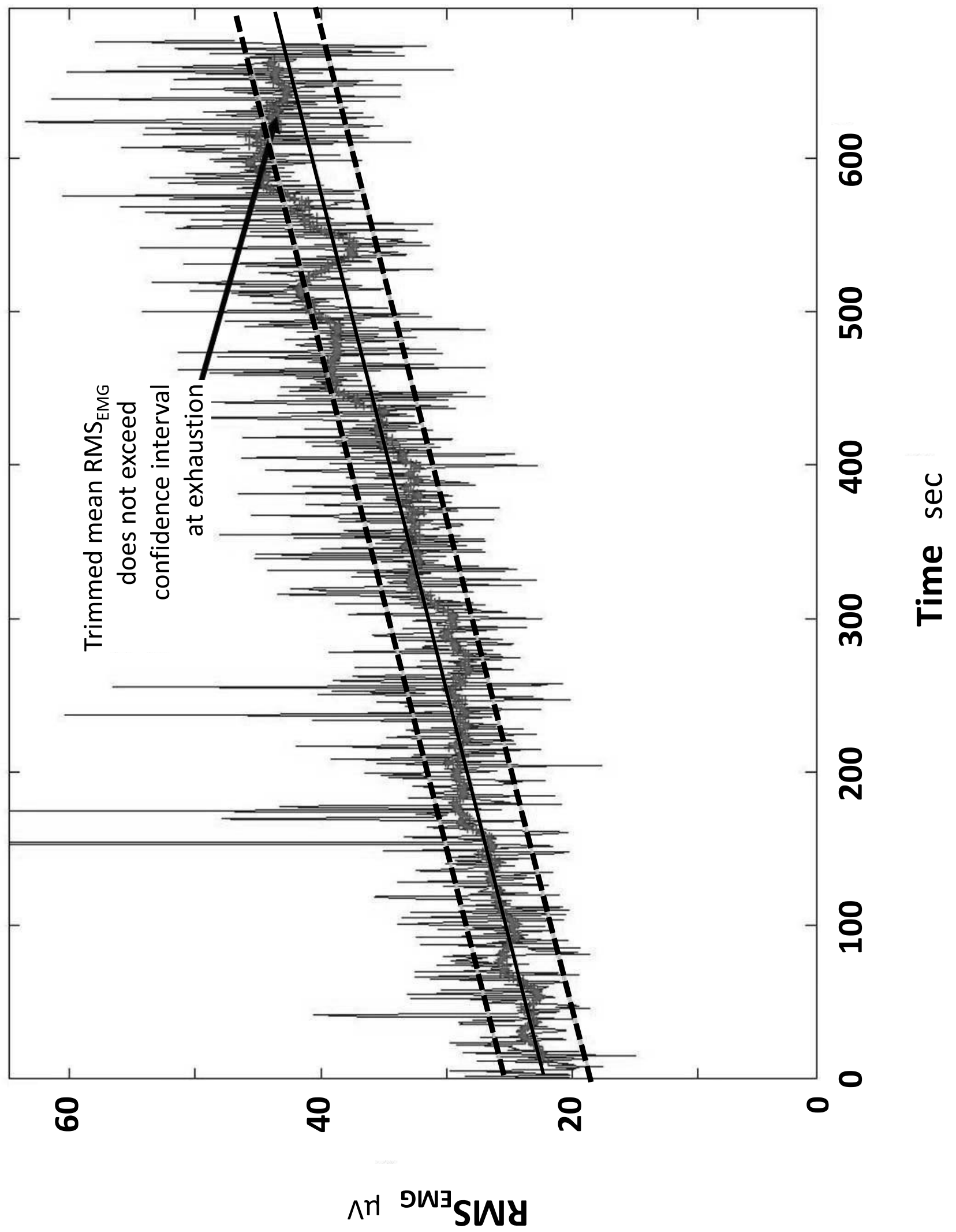



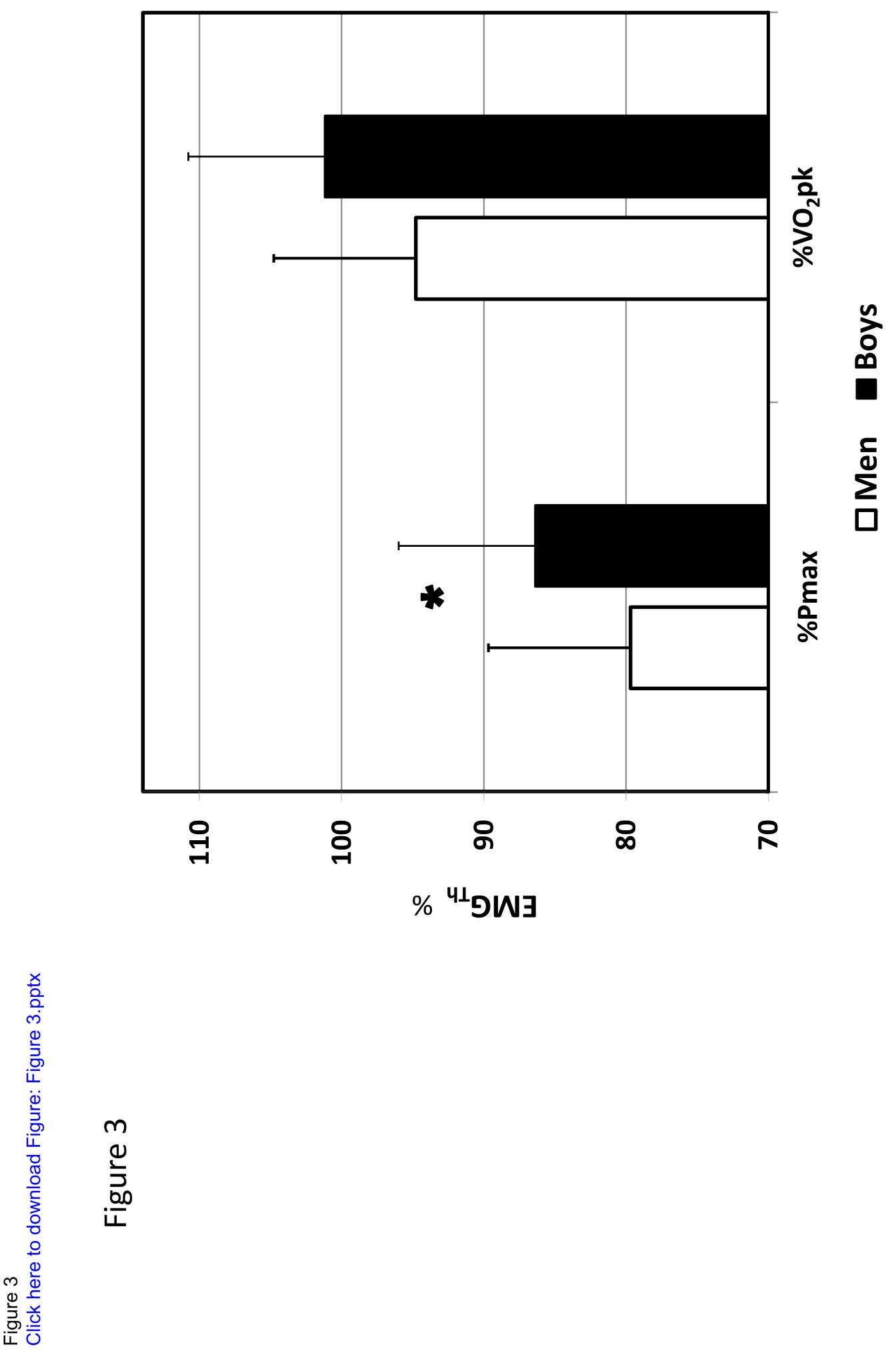

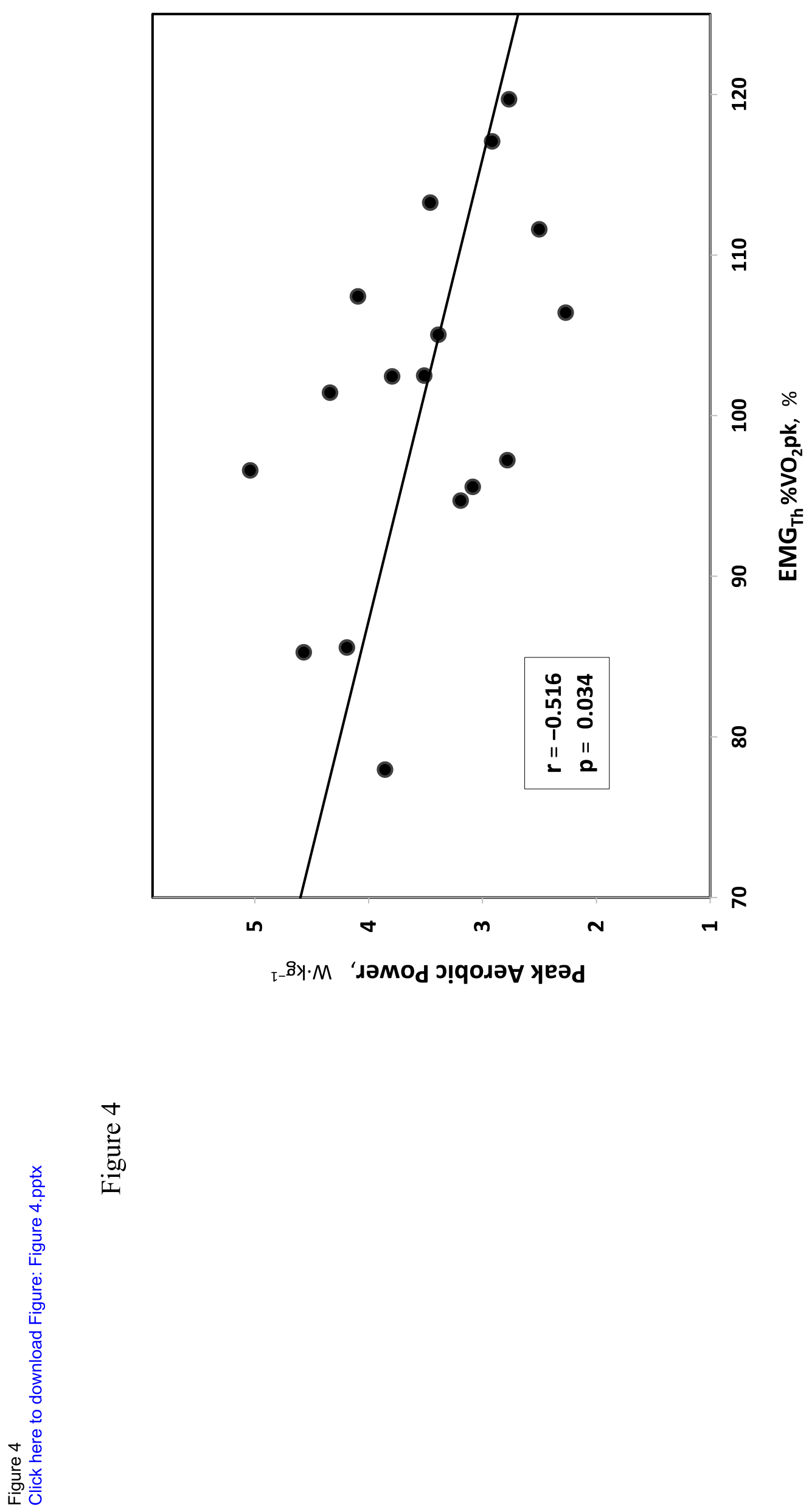